\title{
Methotrexate area under the curve is an important outcome predictor in patients with primary CNS lymphoma: A pharmacokinetic-pharmacodynamic analysis from the IELSG no. 20 trial
}

\section{Joerger ${ }^{*, 1}$, ADR Huitema ${ }^{2}$, S Krähenbühl ${ }^{3}$, JHM Schellens ${ }^{4,5}$, T Cerny', M Reni ${ }^{6}$, E Zucca ${ }^{7}$, F Cavalli ${ }^{7}$ and AJM Ferreri ${ }^{6,8}$}

'Department of Oncology and Hematology, Cantonal Hospital, Rorschacherstrasse 95, St Gallen 9007, Switzerland; '2Department of Pharmacy and Pharmacology, Slotervaart Hospital/The Netherlands Cancer Institute, Plesmanlaan 121, Amsterdam 1066 CX, The Netherlands; ${ }^{3}$ Division of Clinical Pharmacology and Toxicology, University Hospital, Hebelstrasse 2, Basel 4056, Switzerland; ${ }^{4}$ Department of Medical Oncology, Antoni van Leeuwenhoek Hospital/The Netherlands Cancer Institute, Plesmanlaan 121. Amsterdam 1066 CX. The Netherlands; ${ }^{5}$ Division of Drug Toxicology, Department of Biomedical Analysis, Faculty of Pharmaceutical Sciences, Utrecht University, F.A.F.C. Wentgebouw, Sorbonnelaan I6, Utrecht 3584 CA, The Netherlands; ${ }^{6}$ Medical Oncology Unit, Department of Oncology, San Raffaele H Scientific Institute, via Olgettina 60, Milan 20 I 32, Italy; ${ }^{7}$ Oncology Institute of Southern Switzerland, Via Vela 6, Bellinzona 6500, Switzerland; ${ }^{8}$ Unit of Lymphoid Malignancies, Department of Oncology, San Raffaele H Scientific Institute, via Olgettina 60, Milan 20132, Italy

BACKGROUND: This analysis was initiated to define the predictive value of the area under the curve of high-dose methotrexate (AUC $C_{H D-M T X)}$ in patients with primary central nervous system lymphoma (PCNSL).

PATIENTS AND METHODS: We included 55 patients with PCNSL and available pharmacokinetic (PK) data from the International Extranodal Lymphoma Study Group (IELSG) no. 20 trial, randomised to HD-MTX $(n=30)$ or HD-MTX and high-dose cytarabine (HD-AraC) $(n=25)$. Individual AUC HD-MTX from population PK analysis was tested on drug toxicity and clinical outcome using multivariate logistic regression analysis and Cox hazards modelling.

RESULTS: AUC HD-MTX, the IELSG score and treatment group were significant predictors for treatment response (complete or partial) in the adjusted model. The $A \cup C_{H D-M T X}$ did not predict toxicity, with the exception of liver toxicity and neutropaenia. A high AUC $C_{\text {HD-MTX }}$ was associated with better event-free survival $(E F S)(P=0.01)$ and overall survival $(O A S)(P=0.02)$. Both the AUC $C_{H D-M T X}$ and the IELSG score were significant predictors of EFS and OAS in the adjusted model, with a hazard ratio of 0.82 and 0.73 , respectively, per $100 \mu \mathrm{moll}^{-1} \mathrm{~h}^{-1}$ increase in AUC $\mathrm{HD}-\mathrm{MTX}$.

CONCLUSIONS: Individualised dosing of HD-MTX might have the potential to improve clinical outcome in patients with PCNSL, even when administered concurrently with HD-AraC. In the future, this could be carried out by using first-cycle PK modelling with determination of potential dose adaptations for later cycles using Bayesian analysis.

British Journal of Cancer (2010) I 02, 673-677. doi:10.1038/sj.bjc.6605559 www.bjcancer.com

Published online 2 February 2010

(c) 2010 Cancer Research UK

Keywords: methotrexate; high-dose chemotherapy; CNS lymphoma; cytarabine; pharmacokinetics

Primary central nervous system lymphomas (PCNSLs) represent $4-6 \%$ of extranodal non-Hodgkin's lymphomas, but their incidence in the general population is increasing (Ferreri et al, 2003a). High-dose methotrexate (HD-MTX) is a cornerstone of PCNSL treatment (Reni et al, 1997; Ferreri et al, 2002). Only recently, the International Extranodal Lymphoma Study Group (IELSG) concluded the first randomised study in immunocompetent patients with PCNSL (IELSG no. 20). A significant increase in complete remission rate and event-free survival (EFS) was found

*Correspondence: Dr M Joerger; E-mail: markus.joerger@kssg.ch Received 2 November 2009; revised 4 January 2010; accepted 7 January 2010; published online 2 February 2010 when adding high-dose cytarabine (HD-AraC) to HD-MTX (Ferreri et al, 2009). Accordingly, combined HD-MTX/HD-AraC should be seen as the new standard upfront treatment in PCNSL, as it is supported by the best level of evidence available in this disease (Ferreri et al, 2009). Treatment with HD-MTX is hampered by a highly variable pharmacokinetic (PK) behaviour, in part related to renal elimination and the potential for drug interactions (Evans and Christensen, 1985; Thyss et al, 1986; Ferrazzini et al, 1990; Reid et al, 1993; Ronchera et al, 1993; Takeda et al, 2002; Joerger et al, 2006). However, achieving a minimum area under the curve

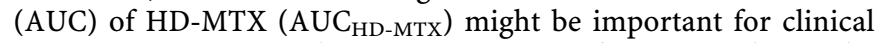
outcome in patients with PCNSL (Ferreri et al, 2004). In this study, we report a PK-pharmacodynamic (PKPD) analysis of HD-MTX in patients enrolled into the IELSG no. 20 trial, to define the 
predictive value of $\mathrm{AUC}_{\mathrm{HD}-\mathrm{MTX}}$ and to identify clinical and therapeutic variables that could be manipulated to improve MTX efficacy in patients with PCNSL.

\section{MATERIALS AND METHODS}

\section{Patient population and treatment}

We included 79 immunocompetent patients with PCNSL, randomised to receive either HD-MTX alone $(n=40)$ or HD-MTX with sequential HD-AraC $(n=39)$ from the IELSG no. 20 trial (Ferreri et al, 2009). High-dose MTX was administered at $3.5 \mathrm{~g} \mathrm{~m}^{-2}$ $\left(0.5 \mathrm{~g} \mathrm{~m}^{-2}\right.$ in $15 \mathrm{~min}$, followed by $3 \mathrm{~g} \mathrm{~m}^{-2}$ as a $3 \mathrm{~h}$ infusion) on day 1 in both arms, and HD-AraC was administered at $2 \mathrm{~g} \mathrm{~m}^{-2}$ as a $1 \mathrm{~h}$ infusion every $12 \mathrm{~h}$ on days 2 and 3 in the combined treatment arm. Radiotherapy was given after chemotherapy in 36 patients, and at progression in 18 patients. Study design and inclusion criteria have been published previously (Ferreri et al, 2009). The determination of MTX serum levels was performed before and immediately after the end of drug infusion, and repeated every $24 \mathrm{~h}$ until the MTX serum concentration fell under the threshold concentration of $0.05 \mu \mathrm{moll}{ }^{-1}$. The concentration data of MTX - collected at $0,24,48,72$ and $96 \mathrm{~h}$ from drug infusion - during the first course of chemotherapy were considered for PK analysis. Leucovorin rescue started $24 \mathrm{~h}$ after the start of HD-MTX infusion, administered at a dose of $15 \mathrm{mg} \mathrm{m}^{-2}$ intravenous push every $6 \mathrm{~h}$ for 12 times or more until MTX serum levels were undetectable. After $48 \mathrm{~h}$ from MTX infusion, leucovorin rescue was modified according to MTX serum levels.

\section{Population PK analysis}

Population PK analysis was performed using the nonlinear mixed-effects modelling program (NONMEM) version VI (double precision, level 1.1) (Beal and Sheiner, 1998). First, a basic PK model was developed for MTX concentration-time data. Model selection was based on the minimum value of objective function, the precision of parameter estimates and the fit of the model to the data as approached by graphical plots. Inter-individual variability was estimated using a proportional error model. Second, the following covariates were tested for their relationship with $\mathrm{CL}_{\mathrm{MTX}}$ : patient gender, age, body-surface area (BSA), creatinine clearance ( $\mathrm{CL}_{\mathrm{CREA}}$ according to the Cockroft-Gault formula, assessed before the start of MTX infusion and capped at $140 \mathrm{ml} \mathrm{min}^{-1}$ ), as well as co-medication with anticonvulsant drugs and steroids. Forward selection and backward elimination were used for covariate testing, with a significance level of $P<0.01$.

\section{Toxicity and response assessment}

Adverse events were separately assessed for each chemotherapy course and graded according to the NCI-NCIC CTC version 3.0 (Trotti et al, 2003). The worst toxicity per organ and per patient was considered for analysis. Treatment response was assessed on contrast-enhanced brain MRI performed within 7 days before chemotherapy and repeated after the second and fourth treatment cycle and after WBRT. Response definition was based on changes in tumour size of enhanced lesions on T1-weighted MRI, and following the NCI standardised response criteria (Cheson et al, 1999). In cases with concomitant positive CSF, cytology examination was performed after the second and fourth treatment cycle and after treatment completion. A reduction of $>50 \%$ of cell number was considered PR, whereas a lower reduction was considered SD. The maximum response recorded from treatment start was considered for activity analyses. Follow-up examinations were conducted as reported previously (Ferreri et al, 2003a).

\section{Statistical analysis}

Individual $\mathrm{AUC}_{\mathrm{HD}-\mathrm{MTX}}$ was compared between treatment groups, patient gender and treatment response using Student's $t$-test. Patients were categorised into those having no response to chemotherapy (SD, PD) and responders (CR or PR). Analysis of variance (ANOVA) was used to compare individual $\mathrm{AUC}_{\mathrm{HD}-\mathrm{MTX}}$ with treatment-associated toxicity. To assess any potential relationship between $\mathrm{AUC}_{\mathrm{HD}-\mathrm{MTX}}$ and clinical outcome, the former was categorised into tertiles, with the higher tertile corresponding to an AUC $>980 \mu \mathrm{moll}^{-1} \mathrm{~h}$ and the lower tertile corresponding to an AUC $<830 \mu \mathrm{moll}^{-1} \mathrm{~h}$. Both EFS and overall survival (OAS) were calculated per $\mathrm{AUC}_{\mathrm{HD}-\mathrm{MTX}}$ category using survival analysis and log-rank test, respectively. The following potential predictors for chemotherapy response were studied using multivariate logistic regression analysis: $\mathrm{AUC}_{\mathrm{HD}-\mathrm{MTX}}$ (tertiles), gender, categorical IELSG prognostic score (Ferreri et al, 2003b) (0-1, $2-3,4-5$ points) and treatment group. The following potential predictors for clinical outcome (EFS, OAS) were studied using multivariate Cox hazards modelling: gender, IELSG score, treatment group and $\mathrm{AUC}_{\mathrm{HD}-\mathrm{MTX}}$. Both EFS and OAS curves were calculated using the Kaplan-Meier method, and the log-rank test was used to detect potential differences per $A U C_{H D-M T X}$ category. A previously described threshold of $\mathrm{AUC}_{\mathrm{HD}-\mathrm{MTX}}$ $\geqslant 1100 \mu \mathrm{moll}^{-1} \mathrm{~h}$ (Ferreri et al, 2004) was additionally analysed on chemotherapy response and clinical outcome. All tests of significance were two-sided; $P<0.05$ was considered significant. All statistical analyses were performed using STATA 10.1 software (STATA Corp, College Station, TX, USA).

\section{RESULTS}

\section{Patient population and data set}

Patient characteristics have been described previously (Ferreri et al, 2009). Out of the 79 patients, 55 had available PK data of HD-MTX and were included into this analysis with the following characteristics: median age 56 years, 32 female (58\%) and 23 male (42\%); 30 patients were randomised to receive HD-MTX and 25 patients to combined HD-MTX/HD-AraC, with a median IELSG-score of 2. Patient characteristics of the PKPD subgroup and of the total population were not significantly different. After chemotherapy, 7 HD-MTX and 18 HD-MTX/HD-AraC patients achieved a CR (18 vs 46\%; $P=0.006)$; 9 MTX and 9 MTX/AraC patients achieved a PR, for an ORR of 40 and $69 \%$, respectively $(P=0.009)$. At a median follow-up of 30 months, 31 MTX and $23 \mathrm{MTX} / \mathrm{AraC}$ patients experienced failure (PD, relapse, death), with a 3 -year EFS of 21 and $38 \%$, respectively $(P=0.01)$. In all, $12 \mathrm{MTX}$ and $20 \mathrm{MTX} / \mathrm{AraC}$ patients are alive, with a 3-year OAS of 32 and $46 \%$, respectively $(P=0.07)$.

\section{Population PK model}

The MTX concentration - time data were best described by a linear two-compartment model with first-order elimination from the central compartment. The MTX clearance was $14.91 \mathrm{~h}^{-1}$ (relative s.e. 9.95), with an inter-individual variability of $22.3 \%$ and a residual variability of $31.8 \%$. Volume distribution was 71.91 ( \pm 51.5$)$, with an inter-individual variability of $30.1 \%$. Inter-compartmental clearance was $11.2 \mathrm{lh}^{-1}( \pm 5.2)$, with an inter-individual variability of $35 \%$. Two patients had a $\mathrm{CL}_{\mathrm{HD}-\mathrm{MTX}}>20 \mathrm{lh}^{-1}$, six patients $<7 \mathrm{~h} \mathrm{~h}^{-1}$. Median AUC $\mathrm{HD}-\mathrm{MTX}$ was $931 \mu \mathrm{mol}^{*} \mathrm{l}^{-1} \mathrm{~h}$ (range 486$\left.1710 \mu \mathrm{mol}^{*} \mathrm{l}^{-1} \mathrm{~h}\right)$. The $\mathrm{AUC}_{\mathrm{HD}-\mathrm{MTX}}$ was $<750 \mu \mathrm{moll}^{-1} \mathrm{~h}$ in 11 out of 55 cases with available PK data $(20 \%)$, and $>1100 \mu \mathrm{moll}^{-1} \mathrm{~h}$ in 12 cases $(22 \%)$. Creatinine clearance was the only significant covariate on $\mathrm{CL}_{\mathrm{HD}-\mathrm{MTX}}$, resulting in Equation 1 to describe $\mathrm{CL}_{\mathrm{HD} \text {-MTX }}$ as a function of $\mathrm{CL}_{\mathrm{CREA}}\left(95 \mathrm{ml} \mathrm{min}^{-1}\right.$ is the median 
$\mathrm{CL}_{\text {CREA }}$ as found in the study group):

$$
\mathrm{CL}_{\mathrm{HD}-\mathrm{MTX}}=14.9 *\left(\mathrm{CL}_{\mathrm{CREA}} / 95\right)^{0.368}
$$

The inclusion of patient age, BSA or concurrent administration of HD-AraC did not improve the model fit. The goodness-of-fit plots supported a good data fit of the final model (Figure 1).

\section{Statistical analysis}

The $\mathrm{AUC}_{\mathrm{HD}-\mathrm{MTX}}$ tertiles are outlined across chemotherapy response and clinical outcome in Table 1 . The $\mathrm{AUC}_{\mathrm{HD}-\mathrm{MTX}}$ was not significantly different between treatment groups $\left(902 \mu \mathrm{mol}^{*} \mathrm{l}^{-1} \mathrm{~h}\right.$ in the HD-MTX group, $965 \mu \mathrm{mol}^{*} \mathrm{l}^{-1} \mathrm{~h}$ in the HD-MTX/HD-AraC group, $P=0.16)$. The $\mathrm{AUC}_{\mathrm{HD}-\mathrm{MTX}}$ was significantly higher in the 29 responding patients compared with the 26 cases without chemotherapy response $\left(1075\right.$ vs $\left.867 \mu \mathrm{mol}^{*} \mathrm{l}^{-1} \mathrm{~h}, P=0.0001\right)$. Predictors of a favourable treatment response are outlined in Table 2. Patients with $\mathrm{AUC}_{\mathrm{HD} \text {-MTX }}>1100 \mu \mathrm{mol}^{*} \mathrm{l}^{-1} \mathrm{~h}$ had an odds ratio of 3.5 for having a favourable treatment response $(P=0.03)$. There was no significant relationship between $\mathrm{AUC}_{\mathrm{HD}-\mathrm{MTX}}$ and toxicity, with the exception of liver dysfunction $\left(\mathrm{AUC}_{\mathrm{HD}-\mathrm{MTX}} 1047 \mu \mathrm{mol}^{*} \mathrm{l}^{-1} \mathrm{~h}\right.$ in patients with any treatment-associated liver dysfunction $v s$ $932 \mu \mathrm{mol}^{*} \mathrm{l}^{-1} \mathrm{~h}$ in those without liver dysfunction, $\left.P=0.02\right)$ and neutropaenia ( $\mathrm{AUC}_{\mathrm{HD}-\mathrm{MTX}} 1036 \mu \mathrm{mol}^{*} \mathrm{l}^{-1} \mathrm{~h}$ in patients with grade 3 or 4 neutropaenia $v s 914 \mu \mathrm{mol}^{*} 1^{-1} \mathrm{~h}$ in those with no or grade 1 or 2 neutropaenia, $P=0.007)$. Patients with the highest $\mathrm{AUC}_{\mathrm{HD}-\mathrm{MTX}}$ exhibited a significantly better EFS and OAS as compared with patients in the lower two tertiles of $\mathrm{AUC}_{\mathrm{HD}-\mathrm{MTX}}$ (Table 2 and Figure 2). The $\mathrm{AUC}_{\mathrm{HD}-\mathrm{MTX}}>1100 \mu \mathrm{mol}^{*} \mathrm{l}^{-1} \mathrm{~h}$ was associated with a better EFS and OAS by the log-rank test $(P=0.023$ and $P=0.056$, respectively). Both the $\mathrm{AUC}_{\mathrm{HD}-\mathrm{MTX}}$ and the IELSG score were significant predictors of EFS and OAS using multivariate Cox regression analysis (Table 3). When $\mathrm{AUC}_{\mathrm{HD}-\mathrm{MTX}}$ $>1100 \mu \mathrm{mol}^{*} \mathrm{l}^{-1} \mathrm{~h}$ was introduced into Cox regression analysis as a binary covariate, statistical significance was retained $(\mathrm{HR}=0.51$, $P=0.033$ for EFS, HR $=0.50, P=0.044$ for OAS). No association was found between the volume of distribution, inter-compartmental clearance and any of the clinical end points.

\section{DISCUSSION}

This PKPD analysis of HD-MTX in patients from the IELSG no. 20 trial is of special value, as this is the first prospective, randomised trial in PCNSL with completed accrual (Ferreri et al, 2003a). This study shows that $\mathrm{AUC}_{\mathrm{HD}-\mathrm{MTX}}$ is the most important and independent predictor of clinical outcome in this group of patients. This is an important issue considering the fact that the HD-MTX/HD-AraC combination is the new standard therapeutic approach to patients with PCNSL (Ferreri et al, 2009). Interestingly, this study showed that nearly $75 \%$ of patients did not achieve an $\mathrm{AUC}_{\mathrm{HD}-\mathrm{MTX}}>1100 \mu \mathrm{mol}^{*} \mathrm{l}^{-1} \mathrm{~h}$, which has been previously reported as an independent predictor for improved

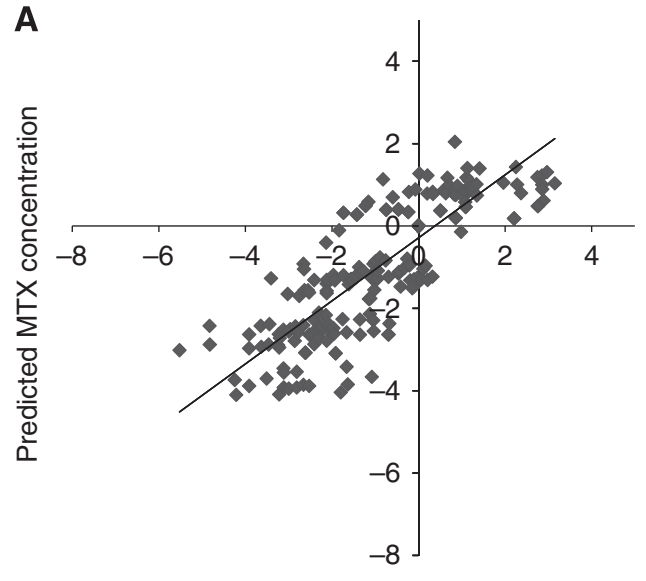

Observed MTX concentration

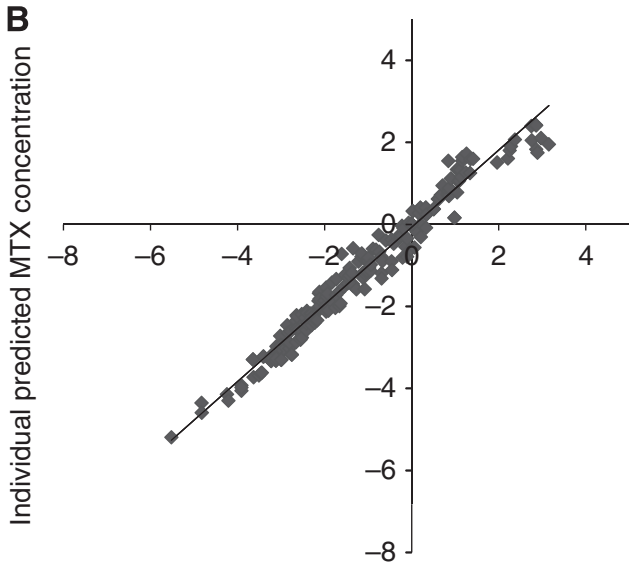

Observed MTX concentration

Figure I Goodness-of-fit plots of the final population pharmacokinetic model (all data log-transformed, drug concentration as $\mu$ mol I ${ }^{-1}$ ). Observed MTX concentrations vs model predictions $(\mathbf{A})$ and vs individual Bayesian predictions (B).

Table I Comparison between AUC HD-MTX tertiles, chemotherapy response and clinical outcome

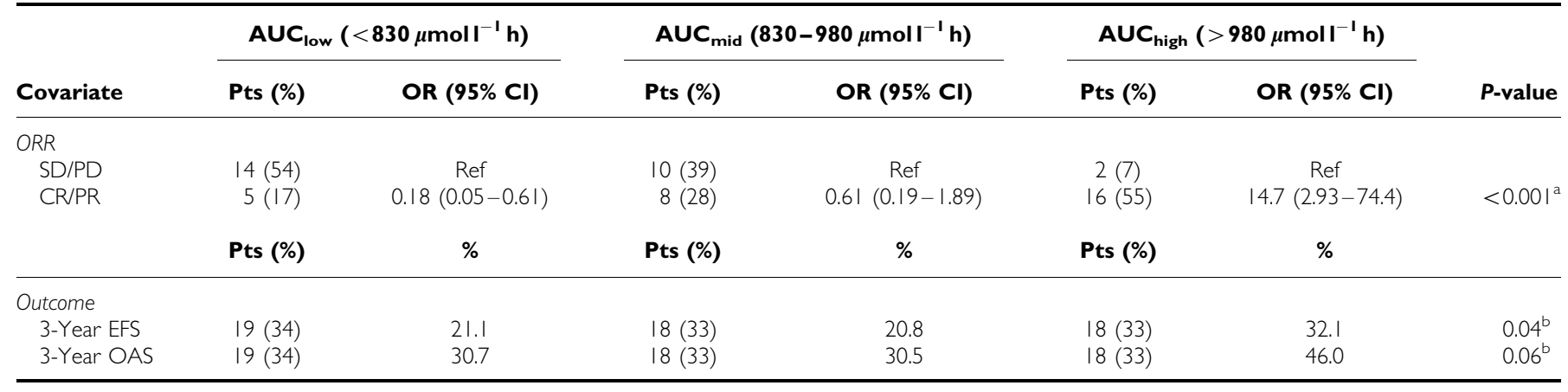

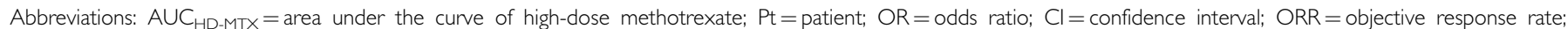
$\mathrm{SD}=$ stable disease; $\mathrm{PD}=$ progressive disease; $\mathrm{CR}=$ complete response; $\mathrm{PR}=$ partial response; Ref $=$ reference; $E F S=$ event-free survival; $\mathrm{OAS}=$ overall survival.

${ }^{a}$ Analysis of variance.

blog-rank test. 
clinical outcome (Ferreri et al, 2004). The present results cannot be interpreted as a lack of benefit from combined HD-MTX/HD-AraC treatment, as not all patients had available PK data for HD-MTX, and combined HD-MTX/HD-AraC treatment was still a significant predictor for clinical outcome when $\mathrm{AUC}_{\mathrm{HD}-\mathrm{MTX}}$ was dropped from the Cox model. It still indicates that inter-individual disparities in HD-MTX pharmacology have an important role in clinical outcome, and that optimising individual $\mathrm{AUC}_{\mathrm{HD}-\mathrm{MTX}}$ is an important strategy for improving clinical outcome in PCNSL. Thus, the encouraging results of the IELSG no. 20 trial (Ferreri et al, 2003a) might be further improved by individualised MTX administration aimed to achieve a target $\mathrm{AUC}_{\mathrm{HD}-\mathrm{MTX}}$ of $1000 \mu \mathrm{mol}^{*} \mathrm{l}^{-1} \mathrm{~h}$. This statement is also endorsed by the fact that there was no relevant impact of $\mathrm{AUC}_{\mathrm{HD}-\mathrm{MTX}}$ on drug toxicity. The strengths of this study include a homogeneous patient population, the availability of detailed response, outcome and toxicity data in

Table 2 Predictors for chemotherapy response (complete and partial remission) using multivariate regression modeling

\begin{tabular}{|c|c|c|c|}
\hline Covariate & OR & $95 \% \mathrm{Cl}$ & $P$-value \\
\hline \multicolumn{4}{|l|}{ Patient gender } \\
\hline Male & Ref & & \\
\hline Female & 0.48 & $0.08-2.92$ & 0.42 \\
\hline \multicolumn{4}{|l|}{ IELSG risk score } \\
\hline $0-1$ & Ref & & \\
\hline $2-3$ & 0.05 & $0.005-0.44$ & 0.007 \\
\hline $4-5$ & 0.03 & $0.002-0.48$ & 0.01 \\
\hline \multicolumn{4}{|l|}{ Treatment group } \\
\hline HD-MTX & Ref & & \\
\hline HD-MTX/HD-AraC & 9.33 & $1.33-65.53$ & 0.02 \\
\hline \multicolumn{4}{|c|}{ AUC $C_{H D-M T X}$ (tertiles, $\mu \mathrm{mol} \mathrm{I}^{-1} \mathrm{~h}^{-1}$ ) } \\
\hline$<830$ & Ref & & \\
\hline $830-980$ & 5.21 & $0.73-37.3$ & 0.10 \\
\hline$>980$ & 121.9 & $7.80-190.1$ & 0.001 \\
\hline
\end{tabular}

Abbreviations: $\mathrm{OR}=$ odds ratio; $\mathrm{Cl}=$ confidence interval; $\quad \mathrm{ELSG}=$ International Extranodal Lymphoma Study Group; HD-MTX=high-dose methotrexate; HDAraC $=$ high-dose cytarabine; $\mathrm{AUC}=$ area under the curve; $\mathrm{Ref}=$ reference.

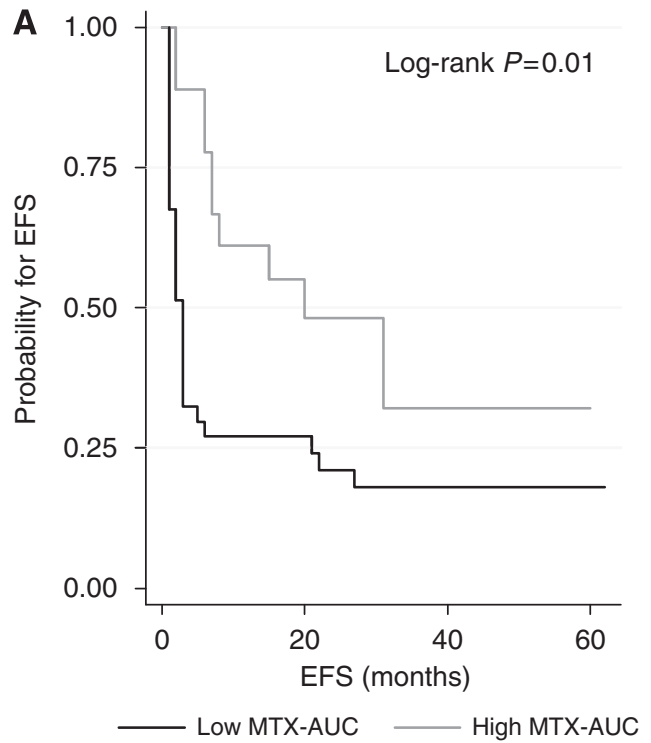

all patients, first-course PK data of MTX in most patients, as well as population PKPD analysis of HD-MTX time-concentration data. The main limitations of this study are that drug interactions between HD-MTX and HD-AraC could only indirectly be studied because no PK data of $\mathrm{HD}$-AraC were available, and $\mathrm{PK}$ data of

Table 3 Predictors for event-free and overall survival using multivariate Cox regression analysis

\begin{tabular}{|c|c|c|c|}
\hline Covariate & HR & $95 \% \mathrm{Cl}$ & $P$-value \\
\hline \multicolumn{4}{|l|}{ Event-free survival } \\
\hline \multicolumn{4}{|l|}{ Patient gender } \\
\hline Female & Ref & & \\
\hline Male & 1.12 & $0.52-2.40$ & 0.77 \\
\hline \multicolumn{4}{|l|}{ IELSG score } \\
\hline $0-I$ vs $2-3$ vs $4-5$ points & 1.71 & $|.04-2.8|$ & 0.03 \\
\hline \multicolumn{4}{|l|}{ Treatment group } \\
\hline HD-MTX & Ref & & \\
\hline HD-MTX/AraC & 0.65 & $0.34-1.25$ & 0.19 \\
\hline \multicolumn{4}{|l|}{$A \cup C_{H D-M T X}$} \\
\hline Per $100 \mu$ mol $I^{-1} \mathrm{~h}$ increase & 0.82 & $0.69-0.98$ & 0.03 \\
\hline \multicolumn{4}{|l|}{ Overall survival } \\
\hline \multicolumn{4}{|l|}{ Patient gender } \\
\hline Female & Ref & & \\
\hline Male & 1.77 & $0.76-4.10$ & 0.19 \\
\hline \multicolumn{4}{|l|}{ IELSG score } \\
\hline $0-1$ vs $2-3$ vs $4-5$ points & 1.82 & $\mid .00-3.31$ & 0.05 \\
\hline \multicolumn{4}{|l|}{ Treatment group } \\
\hline HD-MTX & Ref & & \\
\hline HD-MTX/AraC & 0.80 & $0.39-1.65$ & 0.54 \\
\hline \multicolumn{4}{|l|}{$A \cup C_{H D-M T X}$} \\
\hline Per $100 \mu \mathrm{moll}^{-1} \mathrm{~h}$ increase & 0.73 & $0.59-0.89$ & 0.002 \\
\hline
\end{tabular}

Abbreviations: $\mathrm{HR}=$ hazard ratio; $\mathrm{Cl}=$ confidence interval; IELSG = International Extranodal Lymphoma Study Group; HD-MTX=high-dose methotrexate; $\mathrm{HD}$-AraC = high-dose cytarabine; $\mathrm{AUC}=$ area under the curve; $\mathrm{Ref}=$ reference.

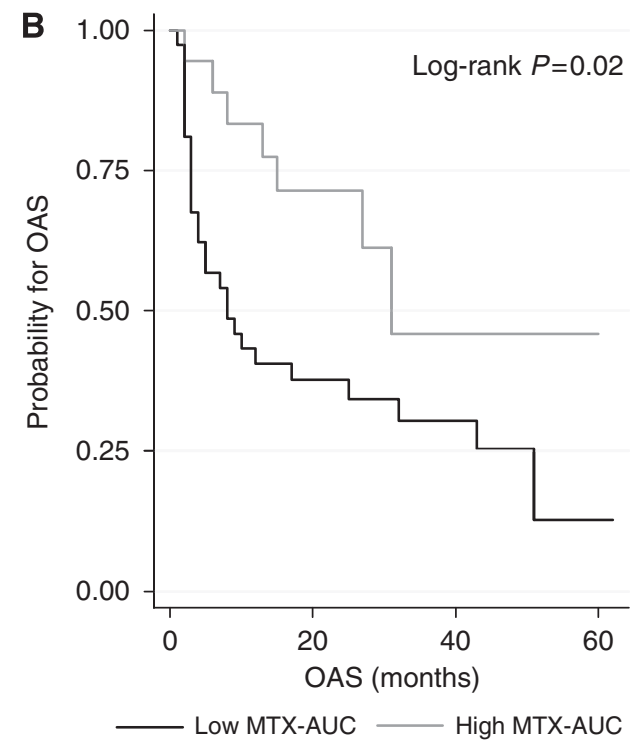

Figure 2 Kaplan-Meier plots for event-free survival $(\mathbf{A})$ and overall survival $(\mathbf{B})$ grouped according to the highest AUC $\mathrm{HD}_{\mathrm{HTX}}$ tertile $\left(>980 \mu \mathrm{mol} \mathrm{I}^{-1} \mathrm{~h}\right)$ and the lower two tertiles of AUC $\mathrm{HD}_{\text {-MTX }}\left(<\left.980 \mu \mathrm{mol}^{*}\right|^{-1} \mathrm{~h}\right)$. 
HD-MTX from later courses were not available. However, the fact that tumour response was usually seen within the first two courses of chemotherapy (Ferreri et al, 2009) does suggest a strong correlation between first-course PK data and clinical outcome.

In a retrospective study (Ferreri et al, 2004), PCNSL patients treated with MTX-based chemotherapy and an AUC HD-MTX $_{\text {. }}$ $>1100 \mu \mathrm{mol}^{*} \mathrm{l}^{-1} \mathrm{~h}$ showed significantly better response and survival rates. In the IELSG no. 20 trial, only $22 \%$ of patients achieved this $\mathrm{AUC}_{\mathrm{HD}-\mathrm{MTX}}$, suggesting room for improving HD-MTX administration. Importantly, a suboptimal AUC ${ }_{\text {HD-MTX }}$ was obtained equally in both treatment arms in the IELSG no. 20 trial. Therefore, the introduction of a personalised dose of HD-MTX, according to patient age, gender and $\mathrm{CL}_{\mathrm{CREA}}$, has the potential to significantly improve treatment activity in these patients, and should be investigated in future trials. According to the present observation, personalisation of the MTX administration schedule should not consider the concomitant use of HD-araC, as the addition of this drug did not change MTX PK. However, this has to be taken with caution, considering the potential for increased toxicity with the combined use of HD-MTX/HD-AraC.

In conclusion, individualised dosing of HD-MTX might have the potential to improve clinical outcome in patients with PCNSL, even when administered concurrently with HD-AraC. In the future, this could be carried out by using first-cycle PK modelling with determination of potential dose adaptations for later cycles using Bayesian analysis.

\section{ACKNOWLEDGEMENTS}

We thank all co-investigators who were actively involved in patient accrual, central radiology review and central pathology review: Marco Foppoli, Maurizio Martelli, Marina Siakantaris, Gerasimos Pangalis, Maurizio Frezzato, Maria Giuseppina Cabras, Alberto Fabbri, Gaetano Corazzelli, Fiorella Ilariucci, Giuseppe Rossi, Riccardo Soffietti, Caterina Stelitano, Daniele Vallisa, Francesco Zaja, Marta Gelemur, Gian Marco Aondio, Giuseppe Avvisati, Monica Balzarotti, Alba Brandes, Maria Joao Costa, Henry Gomez, Attilio Guarini, Graziella Pinotti, Luigi Rigacci, Catrina Uhlmann, Maria AngelopoulouAlberto Franzin, Nicoletta Anzalone, Maurilio Ponzoni, Federico Caligaris-Cappio. We also acknowledge Mrs Cristina Morinini, Mrs Oxanna López, Mrs Monica Bertini, and Mrs Elena Porro (The International Extranodal Lymphoma Study Group, Bellinzona, Switzerland).

\section{REFERENCES}

Beal SL, Sheiner LB (1998) NONMEM User's Guide. NONMEM Project Group, University of San Francisco: San Francisco, CA

Cheson BD, Horning SJ, Coiffier B, Shipp MA, Fisher RI, Connors JM, Lister TA, Vose J, Grillo-Lopez A, Hagenbeek A, Cabanillas F, Klippensten D, Hiddemann W, Castellino R, Harris NL, Armitage JO, Carter W, Hoppe R, Canellos GP (1999) Report of an international workshop to standardize response criteria for non-Hodgkin's lymphomas. NCI Sponsored International Working Group. J Clin Oncol 17(4): 1244

Evans WE, Christensen ML (1985) Drug interactions with methotrexate. $J$ Rheumatol 12(Suppl 12): 15-20

Ferrazzini G, Klein J, Sulh H, Chung D, Griesbrecht E, Koren G (1990) Interaction between trimethoprim-sulfamethoxazole and methotrexate in children with leukemia. J Pediatr 117(5): 823-826

Ferreri AJ, Abrey LE, Blay JY, Borisch B, Hochman J, Neuwelt EA, Yahalom J, Zucca E, Cavalli F, Armitage J, Batchelor T (2003a) Summary statement on primary central nervous system lymphomas from the Eighth International Conference on Malignant Lymphoma, Lugano, Switzerland, June 12 to 15, 2002. J Clin Oncol 21(12): 2407-2414, doi:10.1200/JCO.2003.01.135 [doi];JCO.2003.01.135 [pii]

Ferreri AJ, Blay JY, Reni M, Pasini F, Spina M, Ambrosetti A, Calderoni A, Rossi A, Vavassori V, Conconi A, Devizzi L, Berger F, Ponzoni M, Borisch B, Tinguely M, Cerati M, Milani M, Orvieto E, Sanchez J, Chevreau C, Dell'Oro S, Zucca E, Cavalli F (2003b) Prognostic scoring system for primary CNS lymphomas: the International Extranodal Lymphoma Study Group experience. J Clin Oncol 21(2): $266-272$

Ferreri AJ, Guerra E, Regazzi M, Pasini F, Ambrosetti A, Pivnik A, Gubkin A, Calderoni A, Spina M, Brandes A, Ferrarese F, Rognone A, Govi S, Dell'Oro S, Locatelli M, Villa E, Reni M (2004) Area under the curve of methotrexate and creatinine clearance are outcome-determining factors in primary CNS lymphomas. Br J Cancer 90(2): 353-358

Ferreri AJ, Reni M, Pasini F, Calderoni A, Tirelli U, Pivnik A, Aondio GM, Ferrarese F, Gomez H, Ponzoni M, Borisch B, Berger F, Chassagne C, Iuzzolino P, Carbone A, Weis J, Pedrinis E, Motta T, Jouvet A, Barbui T, Cavalli F, Blay JY (2002) A multicenter study of treatment of primary CNS lymphoma. Neurology 58(10): 1513-1520
Ferreri AJM, Reni M, Foppoli M, Martelli M, Pangalis GA, Frezzato M, Cabra MG, Fabbri A, Corazzelli G, Ilariucci F, Rossi G, Soffietti R, Stelitano C, Vallisa D, Zaja F, Gelemur M, Aondio GM, Avvisati G, Balzarotti M, Brandes A, Costa MJ, Gomez H, Guarini A, Pinotti G, Rigacci L, Uhlmann C, Angelopoulou M, Tirindelli M, Naso V, Franzin A, Anzalone N, Ponzoni M, Zucca E, Caligaris-Cappio F, Cavalli F (2009) High-dose cytarabine plus high-dose methotrexate versus high-dose methotrexate alone in patients with primary CNS lymphoma: a randomized phase 2 trial. Lancet 374(9700): 1512-1520, doi:10.1016/ S0140-6736(09)61416-1

Joerger M, Huitema AD, van den Bongard HJ, Baas P, Schornagel JH, Schellens JH, Beijnen JH (2006) Determinants of the elimination of methotrexate and 7-hydroxy-methotrexate following high-dose infusional therapy to cancer patients. Br J Clin Pharmacol 62(1): 71-80

Reid T, Yuen A, Catolico M, Carlson RW (1993) Impact of omeprazole on the plasma clearance of methotrexate. Cancer Chemother Pharmacol 33(1): $82-84$

Reni M, Ferreri AJ, Garancini MP, Villa E (1997) Therapeutic management of primary central nervous system lymphoma in immunocompetent patients: results of a critical review of the literature. Ann Oncol 8(3): $227-234$

Ronchera CL, Hernandez T, Peris JE, Torres F, Granero L, Jimenez NV, Pla JM (1993) Pharmacokinetic interaction between high-dose methotrexate and amoxycillin. Ther Drug Monit 15(5): 375-379

Takeda M, Khamdang S, Narikawa S, Kimura H, Hosoyamada M, Cha SH, Sekine T, Endou H (2002) Characterization of methotrexate transport and its drug interactions with human organic anion transporters. J Pharmacol Exp Ther 302(2): 666-671

Thyss A, Milano G, Kubar J, Namer M, Schneider M (1986) Clinical and pharmacokinetic evidence of a life-threatening interaction between methotrexate and ketoprofen. Lancet 1(8475): 256-258

Trotti A, Colevas AD, Setser A, Rusch V, Jaques D, Budach V, Langer C, Murphy B, Cumberlin R, Coleman CN, Rubin P (2003) CTCAE v3.0: development of a comprehensive grading system for the adverse effects of cancer treatment. Semin Radiat Oncol 13(3): 176-181, doi:S1053-4296(03)00031-6 [pii];10.1016/S1053-4296(03)00031-6 [doi] 